\title{
ANARQUISTAS “EN MOVIMIENTO”. REDES DE CIRCULACIÓN E INTERCAMBIO EN EL NORTE GRANDE, 1900-1930
}

\author{
“ON THE MOVE” ANARCHISTS. CIRCULATION AND EXCHANGE NETWORKS \\ IN THE NORTE GRANDE, 1900-1930
}

Ivanna Margarucci* y Eduardo Godoy Sepúlveda**

\begin{abstract}
Utilizando una perspectiva metodológica basada en el enfoque transnacional y la relación entre biografía e historia social, en el presente artículo nos proponemos reconstruir las trayectorias de algunos anarquistas "en movimiento", procedentes de Argentina, Chile y Bolivia, como expresión de un fenómeno más general. La movilidad ácrata "transfronteriza", que se configuró en el espacio del Norte Grande entre 1900 y 1930.

A la luz de esos esbozos biográficos, nos proponemos ver el origen y funcionamiento de las redes de circulación e intercambio en que se asentó dicha movilidad, tendidas entre sujetos y grupos libertarios de los tres países. Asimismo, intentaremos ponderar su relevancia para la estructuración del anarquismo en Bolivia y caracterizar la relación que este movimiento libertario local desarrolló con otros, a escala regional y transnacional.
\end{abstract}

Palabras claves: Anarquismo, Norte Grande, internacionalismo, biografía, historia social.

Adopting a methodological perspective based on the transnational approach and the relationship between biography and social history, in this article we propose to reconstruct the trajectories of some "on the move" anarchists from Argentina, Chile and Bolivia, as an expression of a more general phenomenon. The "cross-border" anarchic mobility, which was configured in the Norte Grande space between 1900 and 1930.

In light of these biographical sketches, we propose to see the origin and functioning of the networks of circulation and Exchange in which said mobility was based, spread between libertarian subjects and groups of the three countries. Likewise, we will try to ponder its relevance for the structuring of anarchism in Bolivia and characterize the relationship that this local libertarian movement developed with others, on a regional and transnational scale.

Key words: Anarchism, Norte Grande, internationalism, biography, social history.

\section{Introducción}

Burlar las fronteras de los Estados-nación fue una práctica común, inherente a la subjetividad libertaria, derivada de causas económicas o políticas concretas, pero a su vez congruente con el antiestatismo e internacionalismo defendido en las ideas.

El abordaje en clave teórica e histórica del anarquismo de sujetos y grupos requiere también derribar las fronteras epistemológicas impuestas por el nacionalismo metodológico. Justamente, este ha sido el ejercicio planteado por el enfoque transnacional, el que mediando un replanteo de las unidades analíticas tradicionales y poniendo en diálogo esos diferentes niveles (lo individual y lo local, lo nacional, lo regional y lo transnacional), ha introducido nuevos temas y problemas dentro del campo de los estudios anarquistas (Bantman y Altena 2017). Así lo evidencia el gran número de trabajos desarrollados últimamente, aun cuando como advierten estos autores su foco está puesto en Europa, existiendo pocas producciones historiográficas acerca de otras áreas geográficas y en definitiva una historia transnacional regional antes que verdaderamente global.

En el caso del anarquismo sudamericano, la aplicación de esta perspectiva concentrada fundamentalmente en la vertiente atlántica del subcontinente, ha arrojado aportes significativos, como por ejemplo los de Neto de Oliveira (2009), Van Der Walt y Hirsch (2010), Franco de Godoy (2013), Laforcade y Shaffer (2015), Fernández Cordero (2017), Migueláñez Martínez (2018) y Souza Cunha (2018). Pese a sus diferentes tópicos, estos trabajos han develado la fluidez de dicho espacio, la intensidad de sus desplazamientos y la porosidad de sus fronteras (Galeano y Albornoz 2017: 129).

\footnotetext{
* CeDInCI, UNSAM/CONICET. Buenos Aires, Argentina. Correo electrónico: ivanna.margarucci@ gmail.com

** USACH/UDP. Santiago, Chile. Correo electrónico: edo.godoy.sepulveda@ gmail.com
} 
A partir de la reconstrucción de las trayectorias de algunos activistas y simpatizantes anarquistas "en movimiento" -migrantes o de paso, de ida o de vuelta- procedentes de Argentina, Chile y Bolivia, sostendremos como hipótesis que las anteriores no fueron características exclusivas del eje atlántico. Aunque relegada por esa historiografía, también en el área andina existió una movilidad ácrata "transfronteriza", que siguió el ritmo de la economía del salitre y de la política desplegada en torno a las fronteras del Norte Grande entre 1900 y 1930. Esta circulación, posible por las características específicas de este espacio, se estableció asimismo en redes ${ }^{1}$ de circulación e intercambio tendidas entre sujetos y grupos libertarios de los tres países. A la luz de esos esbozos biográficos, nos proponemos ver el origen y funcionamiento de dichas redes, ponderar su relevancia para la estructuración del anarquismo en Bolivia y caracterizar la relación que este movimiento libertario de raigambre local desarrolló con otros, a escala regional y transnacional.

\section{Inmigración europea y circulación transfronteriza en el sur de América}

Desde fines del siglo XIX, Buenos Aires se destacó por ser un importante foco de recepción de inmigrantes europeos. Expulsados, algunos, por la situación económica de sus países de origen -Italia, España, Alemania, etc.--, perseguidos, otros, por la represión, las oportunidades prometidas en el nuevo hogar distaban de ser realidad: trabajos poco calificados, explotación y condiciones de vida deplorables, fueron antes bien la norma.

Este contexto constituyó el caldo de cultivo para que las ideologías obreras traídas por algunos de ellos, el anarquismo y el socialismo, prendieran con facilidad. Así se fue conformando una clase obrera local, que a partir de esas identidades -teniendo el anarquismo cierta preeminencia hasta 1930 - se organizó sindicalmente y se envolvió en los principales conflictos sociales de la época, dando la batalla por mejorar su situación social más inmediata siempre con un horizonte revolucionario.

De este modo se consumaba la "expansión ultramarina del anarquismo" tal como es definida por Carlos Taibo (2018). Pero como bien explica el autor, esta era, en general, la primera parada de un largo camino. Muchos inmigrantes replicaron el movimiento que los había depositado en esa urbe, dentro del propio espacio argentino -de Buenos Aires, llegaron al interior: Rosario, Santa Fe, Córdoba, Mendoza y Tucumán- y latinoamericano -por ejemplo, a otra "pujante" ciudad como Santiago de Chile-. Buscando nuevas fuentes de trabajo, pero también debido a motivos políticos: la voluntad de difundir el ideal anarquista o la expulsión sancionada con la famosa Ley de Residencia de 1902. Así, desde la capital argentina, el anarquismo adquiriría una proyección nacional y continental.

Sin embargo, el Atlántico no fue la única vía de entrada, ni tampoco el único espacio, por donde los inmigrantes $-\mathrm{y}$ también nativos- circulaban. A ellos se sumaron los contingentes de trabajadores que llegaban por el Pacífico, desde los puertos del Callao, en Perú, y los de Iquique y Valparaíso, en Chile.

En esas ciudades puerto chilenas, junto con la capital, Santiago, el anarquismo logró arraigar firme entre esa población que aparecía como una suerte de marea humana. Y con el de Buenos Aires, continuó con su desplazamiento y actividad proselitista, inundando nuevas geografías de los Andes. Por ejemplo, la región del Norte Grande.

Para Sergio González Miranda, la clave de definición de esta "macrozona", un "espacio transfronterizo" que incluye el norte chileno y argentino y el altiplano boliviano, fueron, antes que la guerra y la diplomacia, las relaciones entre economía y sociedad.

El mismo recurso por el que Chile, Bolivia y Perú se enfrentaron en la contienda del Pacífico (1879-1883), el salitre, determinó el rumbo de las finanzas del Estado del primer país por lo menos durante cincuenta años y configuró una vasta región económica asentada sobre el botín de guerra chileno: la provincia de Antofagasta, antes boliviana, y la de Tarapacá, antes peruana. Un espacio reputado como un "desierto" aun cuando existieron allí importantes asentamientos humanos dedicados a la explotación y distribución del mineral en las oficinas salitreras del interior y los puertos de Antofagasta e Iquique (González Miranda y Leiva Gómez 2016).

Esta área alcanzó una dimensión mayor, andina, donde los "límites fronterizos" -en la teoría, fijos y objetivos- se convirtieron en "líneas de frontera" -móviles y subjetivas-, lo que se explica no solo por el proceso abierto hasta fines de los 20 en torno a la demarcación territorial, sino fundamentalmente por la integración de los llamados "espacios de influencia". Esto es, los "territorios que (...) se integraron a la industria del nitrato, ya 
sea comercialmente o a través de la contratación de mano de obra": Bolivia, desde el eje Potosí-OruroCochabamba y el noroeste de Argentina (González Miranda 2016:22, 58).

Por esas fronteras porosas circularon productos y fuerza de trabajo. También sueños e ideas (Cavieres y Cajías 2008). Amén de la importancia de los viejos caminos de troperos y el arrieraje, los ferrocarriles fueron un protagonista central de esta historia de desplazamientos. Su desarrollo fue paralelo al del ciclo de la economía del salitre, cuyo auge se ubica durante las dos primeras décadas del siglo XX. El Ferrocarril Central Norte unió las principales ciudades de Argentina, entre ellas su capital, con Bolivia. En 1891 comenzó a funcionar el tramo Tucumán-Jujuy y en 1908 llegó hasta La Quiaca, posta fronteriza con Villazón (Bovi 2007: $3,13)$. Sus vías se empalmarían con el ferrocarril entre Villazón-Tupiza-Atocha, cuya construcción se inició en 1915 y concluyó en 1925. Allí se conectaba con el tramo Atocha-Uyuni (1913), y por intermedio de este con el primer ferrocarril entre Chile y Bolivia, que iba de Antofagasta a Oruro (1892), con conexión a La Paz y a Cochabamba (1917). El otro ferrocarril que vinculó a ambos países fue el Arica-La Paz, construido por cuenta y a expensas de Chile, según lo dispuesto en el artículo 3 del tratado de 1904, e inaugurado en mayo de 1913 (Contreras 2003:283-284).

La frontera chileno-boliviana se caracterizó durante este período por ser una "frontera abierta". Allí, el Estado chileno no se preocupó tanto por demarcar la soberanía conquistada a punta de bayoneta con aparatos y agencias estatales, como controles policiales o aduaneros, sino más bien por "dejar hacer" a los empresarios. Estos eran los que requerían, antes que nada, "que la frontera no fuera un límite, sino una línea", de modo de conseguir mano de obra extranjera mediante diversos métodos, como el enganche, para hacer rodar los engranajes de la economía del salitre. La presencia del Estado se sentiría sí en la costa, en los puertos de embarque, al momento de recaudar los impuestos a la exportación del mineral. Después de 1929, con el acuerdo definitivo de Chile y Perú por la cuestión de Tacna y Arica y la imposibilidad de Bolivia de negociar una salida al mar, la frontera acabó por “endurecerse" (González Miranda 2016:40, 82).

Muchas familias bolivianas respondieron a ese llamado. Marcharon desde los departamentos de Oruro y Potosí, empleándose en salitreras, pero también en las minas de cobre y plata de Collahuasi. Un lugar destacado dentro de esta migración le cupo a la población cochabambina (González Miranda 2016:98-99), donde la crisis agraria e industrial -provocada por factores ecológicos y el impacto de la apertura comercial que sobrevino tras la llegada del ferrocarril a Bolivia- se vio "en la dura necesidad de entregar a la emigración su mejores elementos para que vayan a buscar a pueblos extraños los medios" de subsistencia que no les otorgaba el suyo: Argentina, Chile y Perú. "Hay en esos estados barrios de cochabambinos que no olvidan la Patria amada" ("Intereses departamentales", El Heraldo, 22 de enero de 1903).

Como señala el periódico de Cochabamba, efectivamente, los trabajadores bolivianos mantuvieron muchas de sus pautas culturales en la pampa salitrera. Pero también intercambiaron y generaron lazos de solidaridad con los obreros peruanos y chilenos que habitaron y trabajaron, codo a codo con ellos, en ese espacio. Se generó así "una sociedad multicultural", un "territorio trinacional" en el "desierto", que incluía además a otros grupos nacionales: "chinos cantoneses, croatas, italianos, españoles, argentinos, británicos, alemanes, etc." (González Miranda 2016:38, 166).

No son los brazos los que faltan, sino mejor salario, mejor trato y más humanidad (...) La pampa, compañero, es un desierto embrutecedor, indigno de ser habitado por seres humanos. La pampa no es más que un presidio más extenso, donde no se está entre rejas, pero se vive sometido bajo el ojo y el sable feroz del carabinero (Enrique Arenas, "Carta a Luis Cusicanqui", Iquique, 10 de diciembre de 1923).

Así resume las condiciones de vida y de trabajo de los pampinos, un célebre anarquista del Norte Grande. Muchos de sus reclamos aparecen condensados en un importante documento: "Trabajos $\mathrm{y}$ antecedentes presentados al supremo gobierno de Chile", confeccionado por la Comisión Consultiva del Norte que reveló durante 1904 la situación de los trabajadores de las provincias salitreras (Salas Lavaqui 1908).

En el fragor de la explotación y el descontento, se fue configurando una clase obrera local cosmopolita, identificada con el mutualismo, el anarquismo y el socialismo, ideas que desde 
temprano difundieron nacionales y extranjeros. Pero esta distinción, por lo menos hasta la década de 1920, era un sinsentido para ellos. Ya que las agrupaciones político-culturales y sindicales, la prensa, las huelgas y las masacres (Pinto Vallejo 2007; Santibáñez 2018; Grez 2018) de esta temprana época, por ejemplo la de la Escuela Santa María de Iquique en diciembre de 1907, incluyeron por igual a chilenos, peruanos, bolivianos y argentinos ("Ecos de la huelga. Relación de los heridos", $E l$ Nacional, 26 de diciembre de 1907).

Trabajar, vivir, padecer, luchar, morir... Convirtió a muchos de ellos en proletarios "del mundo", antes que los de una "Patria amada", para luego de esta experiencia continuar migrando y difundir el ideal en otras latitudes, como ser, sus países de origen. El control de las cuotas de producción por parte de los empresarios y la crisis endémica-recordemos algunas fechas: 1914, con el inicio de la Primera Guerra Mundial; 1919 y 1921-22, a raíz de la pérdida del mercado alemán; 1930, por la crisis mundial-, agotaban las fuentes de trabajo en las oficinas salitreras y obligaban a los extranjeros a un retorno entre intermitente y masivo.

En las coyunturas más críticas, los Estados de Chile y Bolivia financiaron de hecho la repatriación de cientos de ellos ("Obreros bolivianos y peruanos", El Mercurio, 11 de agosto de 1914; "Patriótica disposición del gobierno de Bolivia”, La Patria, 21 de enero de 1919). El primero, temeroso de posibles estallidos sociales. El segundo, tal vez, debido a un sentimiento de responsabilidad respecto de aquellos a los que aún consideraba ciudadanos nacionales.

La prensa y ciudadanía boliviana, sin embargo, también tuvieron miedo. En cada crisis, los periódicos de Oruro informaban día a día la cantidad de pampinos que colmaban la estación del tren que unía esa ciudad con Antofagasta. El Diario de La Paz, en la coyuntura del 30, advertía "los peligros" inmediatos derivados del éxodo de obreros bolivianos": enfermedades y miseria ("Los peligros del éxodo de los obreros bolivianos", $E l$ Diario, 27 de febrero de 1931). Arte y Trabajo de Cochabamba, una década antes, se preocupaba en cambio por la más grave

Amenaza social, resultado de esta emigración creciente, que acentúa la difícil situación del obrero (...) en sus relaciones de trabajo, es la que se refiere a esa especie de snobismo burdo, desaforado y audaz que traen los repatriados de las salitreras (...) De este grupo temible, en cuyas manos brilla el corvo asesino, han salido los forajidos criminales (...) que espantan a los moradores tranquilos de nuestros campos. Por eso es más temible el "roto boliviano" que el verdadero de Chile ("Del ambiente y la crítica", Arte y Trabajo, 30 de noviembre de 1922).

El miedo de la prensa, en efecto, era justificado. Desde principios de siglo, el tránsito de determinados sujetos por el espacio del Norte Grande, había tenido un mismo sentido de "amenaza social" para las clases dominantes de Bolivia. Y de organización y lucha para los sectores subalternos.

\section{De los anarquistas "en movimiento" al movimiento libertario en Bolivia}

Reconstruir algunos fragmentos de la vida de estos anarquistas "en movimiento" - "átomos sueltos" en palabras de Christian Ferrer-, se plantea aquí como un ejercicio que busca superar la mera historia individual. Los últimos aportes en el campo de los estudios anarquistas y la historia social van, de hecho, en esa dirección ${ }^{2}$.

Por ejemplo, para el mismo Ferrer (2006:26), no es posible analizar las prácticas políticas y culturales del anarquismo sin considerar la labor desarrollada por sus militantes, ya que fueron ellos quienes vehiculizaron las ideas y las "tomaron en serio", lo que suponía "volverlas una parte de la existencia tan ineliminable como lo es la actividad de cualquier otro órgano corporal".

De forma análoga, otros autores ven en la biografía un complemento (ya no la antítesis) de la historia social, la que permite recomponer no solo la trayectoria del sujeto libertario como personaje complejo y multifacético, sino también la de una generación política y cultural más amplia. La vida del biografiado adquiere así una "naturaleza coral", es decir, representa a un conjunto que integra, a una trayectoria mayor de la que es parte (González 2015:26), emergiendo como la clave de acceso y comprensión de ese entorno particular. Así entendido, dicho género no es un fin en sí mismo, sino resulta una forma de acercamiento a la historia de una cultura política -la anarquista-, de fisonomía híbrida -contradictoria en ocasiones-y de naturaleza no monista (Barrio 2015). 
Como sintetiza Chris Ealham (2016:18) a propósito de José Peirats y la historia del anarcosindicalismo español: "la historia social tiene mucho que aportar al campo, más antiguo, de la biografía, ya que está claro que las historias de vida y experiencias forman parte de las historias más amplias de los grupos sociales", las que, como veremos a continuación, pueden articular distintos niveles que van desde lo local a lo regional y transnacional.

Inicios de 1900. Federico C. Martínez, argentino, "comerciante" y "agente de Caras y Caretas", revista de Buenos Aires, llegaba a Tupiza, Bolivia. Seguramente a lomo de mula. El Ferrocarril Central Argentino tenía sus puntas de rieles en Humahuaca. El de Atocha a Villazón no existía. Sin embargo, Tupiza era ya, para ese entonces, la puerta de entrada desde Argentina a Bolivia: de personas, también de productos y de ideas.

El 21 de febrero de 1907 Martínez fue "deportado por las autoridades bolivianas so pretexto de anarquismo" desde Tupiza a Chile. Su periplo debe haber sido, al menos por el Norte Grande, en tren: Uyuni, Ollagüe, Antofagasta -aquí, trabajó dos meses para conseguir dinero-, Santiago y Buenos Aires. La expulsión se efectuó "con la comodidad de toda supresión de fórmulas legales", dice Caras y Caretas, pues no existía aún la Ley de Residencia (sancionada en Bolivia, en 1911). La misma revista destaca los "vituperios" de la prensa local y la "indignación natural de un pueblo culto y civilizado en presencia de un hecho que se le aparece exótico"; pero también ella misma protesta por la injusticia que pesa sobre un hombre reputado como honorable ("El deportado de Bolivia", Caras y Caretas, $27 \mathrm{de}$ julio de1907).

El anarquismo, en verdad, no era un "hecho exótico". En Tupiza había surgido en 1905 la Unión Obrera $1^{\circ}$ de Mayo, primera agrupación de Bolivia identificada con las ideas libertarias, que nucleaba "un considerable número de socios" artesanos, tenía una biblioteca compuesta de los clásicos del anarquismo y editaba el periódico Aurora Social, cuya "aparición nos da a entender que la clase obrera boliviana, al igual de la chilena, va dándose cuenta del papel que en el mundo capitalista representa" ("Vida obrera internacional. Bolivia", Aurora Social, 30 de noviembre de 1906).

De hecho, en ese mismo número de este órgano de prensa aparecen dos avisos publicitarios, uno donde Federico Martínez ofrecía sus servicios de "comisionista, consignatario y agente aduanero en
Tupiza" y otro en el que sus "sucesores" publicitaban el "Gran Hotel Internacional". Anarquista o chivo expiatorio, Martínez pautaba en Aurora Social, lo que Caras y Caretas muestra como prueba del presunto delito. La importancia del hecho radica en la propia acción, tal vez la primera, del gobierno boliviano contra el anarquismo.

En el número nueve de Aurora Social, además de repetirse la publicidad -todavía Martínez no había sido deportado-, aparece publicado el artículo "La mujer y el socialismo", firmado por un tal "Franco Villa" ("La mujer y el socialismo", Aurora Social, 31 de enero de 1907). ¿Francisco Villa?, si es que ese era su nombre verdadero -y no un seudónimo robado de la revolución mexicana-. Ferroviario, italiano "venido muy joven [desde la Argentina] y radicado hace muchos años" en Oruro, debido a su activismo sindical -en la Federación Obrera del Trabajo de Oruro (1919) y en la Federación Ferroviaria (1920)- fue también deportado en junio de 1922. Ahora sí, mediante la Ley de Residencia, tal como justificaba el propio presidente Saavedra, ya que "es anarquista y hace propagandas de ese género entre los elementos obreros. Convendría que ferroviarios no solidaricen con elemento peligroso y extranjero (...) Los elementos extranjeros siembran ideas antipatrióticas, pretendiendo borrar el sentimiento de la patria y predican procedimientos netamente anarquistas" ("Por ahí debía comenzar", Arte y Trabajo, 18 de junio de 1922). El caso de Villa y el temor de Saavedra ilustran la sagaz observación de Lora (1969:425) respecto del papel jugado por los ferrocarriles -"verdaderos canales revolucionarios"- en la historia boliviana.

Poco sabemos de las conexiones ácratas de Martínez o Villa allende las fronteras. Conocemos sí acerca de aquellas que desarrollaron las agrupaciones a las que estuvieron afiliados: Montevideo, Rio de Janeiro, Lima la de Tupiza; Buenos Aires y Lima, la de Oruro. Entre esos vínculos, es importante destacar los más fluidos lazos que mantuvieron con Chile. Por ejemplo, la Unión Obrera $1^{\circ}$ de Mayo con la Combinación Mancomunal de Obreros de Antofagasta y, más al sur, la Combinación Mancomunal de Obreros de Coquimbo: con la primera, intercambiaba publicaciones y contactos en el exterior, a la segunda, le daba información del naciente movimiento obrero boliviano ("Notas sueltas", El Marítimo, 8 y 15 de julio de 1906; "Movimiento obrero. Bolivia", El Trabajo, 29 de diciembre de 1906). Y la Federación Ferroviaria 
surgió pues a propósito de la solidaridad desplegada con los trabajadores ferroviarios chilenos en la huelga de diciembre de 1919 ("La huelga se hace general en toda la línea hasta La Paz", El Socialista, $1^{\circ}$ de diciembre de 1919), hecho que determinó la escisión de los comités de Uyuni y de Oruro de la Liga de Empleados y Obreros de Ferrocarriles y la constitución de esta más combativa federación, que agrupó a los trabajadores de la seccional boliviana del Ferrocarril Antofagasta-Oruro (Lora 1969:409).

En un medio local donde el movimiento obrero se encontraba aún en un momento de gestación, la supervivencia de estos tempranos grupos anarquistas o federaciones sindicales dependía en buena medida de sus relaciones internacionales. El núcleo básico de relacionamiento fue el más próximo, también más "desarrollado" políticamente hablando: el Norte Grande. Pero estas redes, por donde circulaban personas, materiales, informaciones, contactos y apoyo a los conflictos, no fueron "mallas" estrechas. Cuando fue posible, excedieron el marco regional, para proyectarse a ciudades tan distantes como las que mencionamos y, también, Santiago de Chile.

Algunos años después que Martínez, llegaba a Bolivia otro extranjero: el zapatero español José Clota. Había arribado a América, a comienzos de siglo. Probó suerte en Buenos Aires, no la halló y fue hacia Santiago, donde decía "comencé a ganarme el sustento con el sudor de mi frente. Robando tiempo a mis ocupaciones, colaboraba también en un periódico anarquista" ("Un anarquista en La Paz", La Batalla, $2^{\mathrm{a}}$ quincena de mayo de 1914). Por vender este diario en la vía pública, La Batalla, fue arrestado en octubre de 1913 (Margarucci y Godoy Sepúlveda 2018:147-148) y luego denunciado por el almirante Alberto Silva Palma ante el Intendente de Santiago en El Mercurio, quien emula las palabras de Saavedra al referir: "este pueblo patriota no está dispuesto a tolerar que esos extranjeros hambrientos vengan a inocularnos nocivos y perturbadores principios" (Grez 2007:252).

Clota le respondió al Almirante, pero cansado de la falta de "libertad de pensamiento" que en su deambular ansiaba encontrar en Chile e interesado quizás en difundir sus ideas en otra parte, rumbeó entre fines de 1913 y comienzos de 1914 a La Paz. Sin lograrlo; pues "las autoridades [de La Paz] apenas impuestas de su presencia ordenaron su deportación" ("Varios", La Batalla, $1^{\text {a }}$ quincena de mayo de 1914).
Hace dos días [el 16 de abril] fue sorprendido por un "pesquisa" en amena charla con su camarada. Hablaba el de referencia, con calor, con entusiasmo, convencido, sobre el socialismo, comunismo y anarquismo, que tantos apóstoles y propagandistas cuentan esas doctrinas, en el orbe como Reclús, Marx, Kropotkine, Ferrer y otros (...) Definió la doctrina del socialismo, como la única que ha de redimir a los obreros de la postración en que yacen ("Un anarquista en La Paz", La Batalla, 2a quincena de mayo de 1914).

El policía lo capturó y lo condujo "del pescuezo a la comisaría central (...) La consiguiente protesta fue vana (...) Se trataba de un anarquista $\mathrm{y}$, por consiguiente, de un individuo peligroso (...) Era menester aislar a ese jermen nocivo" ("Un anarquista en La Paz", La Batalla, $2^{\mathrm{a}}$ quincena de mayo de 1914), primero con la cárcel, luego con el destierro, que lo depositará, de nuevo, en Chile.

Algunos meses después, probablemente movidos por la curiosidad que había despertado la experiencia boliviana del camarada desterrado, llegará a la capital paceña un grupo de corresponsales de La Batalla, en donde buscan recabar allí información "acerca del movimiento obrero i de la propaganda de nuestras ideas". Poco hallaron. Se lamentaban: "Qué lástima! Qué retraso increíble!" ("Correspondencia en Bolivia", La Batalla, 1" quincena de enero de 1916).

La presencia durante la década del 10 en $\mathrm{La}$ Paz de Clota primero, de esos corresponsales después, es significativa, pues permite pensar las redes de circulación e intercambio tejidas entre Chile y Bolivia, dentro de un espacio mayor a aquel circunscripto al del Norte Grande. Quizás sea posible imaginar esta superposición de vínculos próximos y lejanos a partir de la idea de una "red internacional de redes", unidas mediante ciertos sujetos o grupos que funcionaban como enlaces o "nodos" (Bantman y Altena 2017: 3, 12). Una imagen que cobra fuerza en la medida en que, como veremos, el nexo La Paz-Santiago fue persistente: durante la siguiente década, de la mano de otros activistas y emprendimientos editoriales, los lazos se mantuvieron e incluso replicaron.

Antes que Clota llegara desde Chile a Bolivia, Luis Cusicanqui Durán había hecho el camino inverso. Junto con dos paisanos -Luis Abaroa y 
Jacinto Centellas-migró a las salitreras "en la época (...) [de] la masacre de Iquique (...) Entonces entró con cierta gente que ya dominaba ciertos aspectos sociales, que eran estos también chilenos" (Alberto Cusicanqui comunicación personal 2014). De vuelta en Bolivia, con esa experiencia política a cuestas, se incorporó al Centro Obrero Libertario (COL, 1922) de La Paz, un grupo de estudio y propaganda compuesto por trabajadores, que miró, no tanto hacia Chile, sino hacia Argentina y se relacionó con la porteña Federación Obrera Regional Argentina (FORA) (Margarucci 2020). Abaroa y Centellas serán sus entrañables compañeros de militancia en esta y otras agrupaciones, animadas por la impronta organizativa y activa participación de Cusicanqui: la Federación de Artes Mecánicas y Ramas Similares (1921), el Grupo Libertario La Antorcha (1923), la Federación Obrera Local (1927). Tres hombres que con su trayectoria iluminan la de otros muchos migrantes, los que, como ellos, volvieron de las salitreras convertidos en los ideólogos y organizadores de un movimiento libertario boliviano que así dejaba atrás su etapa de nacimiento.

Para 1923 un mismo pedido aparecerá en los periódicos ácratas de la región. El Grupo Libertario La Antorcha les solicitaba el envío de correspondencia, en especial, "folletos, periódicos y hojas de propaganda en cantidad" para cumplir una tarea de "perseverante difusión idealista. Dirigir todos los periódicos y folletos a (...) Luis Cusicanqui" ("La propaganda anarquista en Bolivia", La Antorcha, 16 de noviembre de 1923) - publica La Antorcha de Buenos Aires-: "Rogamos a la prensa anarquista de todo el mundo la reproducción de esta nota" -agrega La Protesta de la misma ciudad ("Grupo La Antorcha. La Paz, Bolivia", La Protesta, 14 de noviembre de 1923)-. El mismo comunicado fue reproducido con leves variantes por Tribuna Libertaria de Santiago y El Sembrador de Iquique ("Bolivia. La represión gubernamental. Surgimiento libertario del proletariado", Tribuna Libertaria, $1^{\text {a }}$ quincena de diciembre de 1923; "Agrupación Libertaria 'La Antorcha”, El Sembrador, 27 de octubre de 1923).

Las cartas de respuesta a esos avisos colman el "Archivo Luis Cusicanqui" que resguarda el Colectivo Ch'ixi de La Paz. Proceden de distintos lugares del exterior, aunque la mayoría son de dos países: Argentina y Chile, casi en igual proporción. Entre las esquelas descubrimos cuatro que van de diciembre de 1923 a mayo de 1924 con la firma de Celedonio Enrique Arenas Robles (“E. Arenas R.”), obrero tipógrafo que tuvo en la pampa salitrera un rol similar al de Cusicanqui en el altiplano. Arenas colaboró en periódicos ácratas desde Santiago a Antofagasta. En Iquique organizó y participó del Centro de Estudios Sociales La Brecha (1915). Se incorporó en 1917 al grupo editor del periódico El Surco. En 1922 pasó a dirigir el semanario El Sembrador, órgano del primer centro. Ocupó la misma posición en el Sindicato de Cargadores de esa ciudad, punto neurálgico de la propaganda libertaria en el Norte Grande y también en el exterior (Margarucci y Godoy Sepúlveda 2017 y 2018:260-261).

El tono de sus palabras, en esas cartas, hace pensar en un contacto fluido. Desde Chile, remitía materiales en cantidad, El Sembrador -al que Cusicanqui ponderaba como "nuestro semanario", "piedra angular" de Chile y de Bolivia ("Adelante", El Sembrador, 1 de septiembre de 1923)-y el folleto "En Tiempo de Elecciones" de Errico Malatesta (Enrique Arenas, "Carta a Luis Cusicanqui", Iquique, 1 de abril de 1924 y 20 de mayo de 1924). Como antes la FORA con el COL, el tipógrafo nortino hacía de enlace entre La Antorcha y la Asociación Internacional de Trabajadores (1922) de Alemania, interesada en "trabar relaciones con los compañeros de Bolivia, a fin de que vosotros le proporcionéis datos sobre el movimiento proletario de esa región" (Enrique Arenas, "Carta a Luis Cusicanqui", Iquique, 7 de marzo de 1924). Arenas también respondía a los interrogantes de Cusicanqui acerca de, por ejemplo, la falta de brazos en las salitreras, a las que hacía tiempo había ido a trabajar. Sus palabras, evocadas líneas más arriba, intentan retratar las terribles condiciones de trabajo y de vida de los habitantes del rico "desierto".

Luis Cusicanqui se erigió así una suerte de "embajador libertario", el "nodo" boliviano de esa vasta "red internacional de redes". Dos sujetos que formaban parte de esta vasta red se dirigirán desde el norte de la Argentina y el centro de Chile y convergerán en Bolivia en un momento clave para el movimiento libertario local.

Uno de ellos fue Mario Forti, también conocido como Mario Fortunati y Tomás Soria. Seudónimos, los dos, del anarquista italiano Renato Rocco Giansanti, quien hizo suya la ruta Tucumán-Tupiza-La Paz, transitándola de ida y de vuelta varias veces a lo largo de su vida, para sembrar la semilla libertaria en la región. En la primera ciudad integró la agrupación Brazo y Cerebro (1922) y colaboró en el 
periódico Adelante! Víctima de la persecución -el rumor dice que se vio implicado en la muerte de un esquirol-, siguió las vías del tren a La Quiaca y de ahí a Tupiza, donde se instaló con su familia y montó una imprenta y la librería "Renacimiento". En ocasiones, firmaba sus crónicas desde La Paz. Rápidamente retomó los vínculos ya existentes entre el anarquismo tucumano y el boliviano ${ }^{3}$ y se relacionó con Luis Cusicanqui y otros camaradas para colaborar con ellos de diversas maneras. ¿Cómo?

Escribiendo y difundiendo en la prensa anarquista de Argentina -La Antorcha porteña, también La Obra de Tucumán-acerca de la situación social y política de Bolivia.

Intercambiando material y dotando a los bolivianos, al igual que Arenas, de contactos claves en el extranjero. En 1927 promovió la visita de Antonio Fournarakis a Bolivia, anarquista griego, otro trotamundos, que mantuvo un nutrido intercambio epistolar con Cusicanqui. Sus cartas y más tarde sus pasos, siguieron las principales estaciones del Ferrocarril Central Norte -Tucumán, La Quiaca-, para llegar, otro tren mediante, a Tupiza y luego a La Paz ("Cartas a Luis Cusicanqui", Tucumán, 24 de marzo de 1927 y La Quiaca, 2 de junio de 1927 ).

Implicándose como parte del movimiento local y aportando desde lo organizativo, incluso más allá de esa capital. "Las secretas actividades de Soria parecen haber sido particularmente intensas desde 1926 y con su apoyo el grupo La Antorcha extendió su influencia (...) formando núcleos artesanales anarquistas en Corocoro, Poopó y Uyuni” (Rodríguez García 2010: 60).

Entre fines de 1920 y comienzos de 1930 Soria volvió a Tucumán. Continuó involucrado con el movimiento, no solo argentino, también boliviano, para fundar en 1946 con su hijo Liber Forti y otros, la agrupación Nuevos Horizontes de Tupiza, dedicada a la propaganda anarquista y al teatro social. Los lazos con Cusicanqui perduraron de la misma manera que su convicción en el ideario y organización ácrata.

En una carta tardía que lo tiene a Soria por destinatario, Cusicanqui le propuso editar una "viografia del Sindicalismo Boliviano", que según decía iría a escribir

Con toda la ducumentación presisa del pasado y si falta vuscare en esta de compañeros viejos que deben tener material y por lo visto las fallas gramaticales estaria a tu cargo, sin q por ello sea un obstaculo para la vuena presentación de (...) nuestra obra (Luis Cusicanqui, "Carta a Tomás Soria", La Paz, 22 de marzo de 1955).

Lamentablemente, el proyecto jamás se concretó. Solo nos quedan los retazos de estas magníficas historias de solidaridad y de amistad proletaria, que nos acercan la prensa y las cartas.

Armando Triviño, chileno, zapatero -como Clota-, inicialmente ligado a los periódicos $L a$ Batalla -también como Clota y Arenas- y Verba Roja del que fue su director, y más tarde, a la International Workers of the World (IWW) chilena, encontró en 1927 a Soria y Fournarakis en La Paz.

Huía, al igual que Clota la década anterior, de la represión del gobierno "militarista y mazorquero" de Ibáñez del Campo. La correspondencia de Roberto Losada dirigida a Luis Cusicanqui describe la odisea que le tocó padecer a decenas de anarquistas y comunistas como Triviño: la detención en Santiago y el traslado a Valparaíso, para ser confinados en "la Isla de Mar Afuera (...) en donde se les hará trabajar y se les tendrá bajo un régimen disciplinario militar" (Roberto Losada, "Carta a Luis Cusicanqui", Santiago, 18 de marzo de 1927). Destino que aquel logró sortear, haciéndose pasar en Valparaíso por un boliviano deseoso de volver a su patria (Muñoz 2009: 41), para después de atravesar la pampa salitrera, llegar a la capital de Bolivia.

¿Por qué eligió tal nacionalidad falsa y destino? Probablemente porque activó las redes preexistentes tendidas entre los movimientos libertarios de ambos países. Sabemos ya de la relación entre La Batalla y el anarquismo de La Paz. Seguramente, quienes editaban Verba Roja también se hayan carteado con libertarios de esa ciudad. Hay, por ejemplo, una carta firmada por A. ¿Aruzny? procedente de Santiago, quien se afana de haber remitido una anterior, de Cusicanqui, "al periódico Verba Roja editado (...) por la agrupación anarquista La Tierra" (A. ¿Aruzny?, "Carta a Luis Cusicanqui”, Santiago, 21 de enero de 1924).

Ya en La Paz, Lora (1970: 63) apunta el nombre "Treviño" junto con el de los otros anarquistas extranjeros y los responsabiliza por aquella que sería en "gran medida" obra colectiva suya: "las organizaciones ácratas" de Bolivia. Una afirmación que habría que matizar, pero que indudablemente es significativa.

Allí encontró a Triviño, de nuevo, igual que a Clota, la represión. Detenido en el panóptico de 
San Pedro, huyó a fines de 1927 a Buenos Aires -“después de haber dejado atrás" las estaciones del tren que llega a Villazón: "Oruro, Uyuni (...) Atocha (...) Tupiza" ("Cosas y hechos de Bolivia", Humanidad. Revista libertaria, marzo de 1928)-en donde permaneció hasta la década del 30 colaborando activamente con los movimientos anarquistas de Argentina y Chile.

El anarquista chileno intentó capturar la esencia de la vida en el altiplano y legársela a sus compañeros de ideas de la región rioplatense. En la revista porteña Humanidad dejó una semblanza de su estadía en Bolivia. Su historia y geografía lo conmueven; el panóptico, algunas costumbres de La Paz y principalmente las injusticias sociales, le provocan un sentimiento repulsivo ("Cosas y hechos de Bolivia", Humanidad. Revista libertaria, marzo, mayo y julio de 1928). Triviño escribía desde el punto de vista del hombre blanco; de hecho, al comienzo de esa saga (publicada inicialmente en La Antorcha) reproduce los estereotipos - del indio, de la chola- de la oligarquía racista ("Cosas y hechos de Bolivia", La Antorcha, 2 de febrero de 1928). A pesar de ello continuaría practicando el internacionalismo: ayudando, con Fournarakis, a los compañeros de Bolivia en la edición de un periódico propio $-\mathrm{La} \mathrm{Tea-}$, intentando mantener los lazos con ellos. En una carta a Cusicanqui, le preguntaba por la falta de comunicación y le insistía: "escríbame [...] Yo siempre los recuerdo y de buenas ganas volvería a verlos y a luchar con vosotros" (Armando Triviño, "Carta a Luis Cusicanqui", Buenos Aires, sin fecha).

Los caminos que habían sido de ida, ahora eran de vuelta.

\section{A modo de conclusión. De lo local a lo transnacional}

¿Qué tienen en común los anteriores esbozos biográficos? Son las historias de algunos sujetos, de aquellas que seguramente fueron sus mayores proezas. Siguen la ruta de sus movimientos, voluntarios o compulsorios. Siguen la traza de la rebeldía. Además de individuos, fueron seres sociales, parte integrante de un movimiento, de un proyecto más amplio que los trascendió. De hecho, fueron ellos mismos -sin saberlo, quizás- el punto neurálgico del desarrollo del anarquismo en este rincón de los Andes. De ahí su enorme y potencial capacidad narrativa, proyectiva y heurística.
Estos anarquistas "en movimiento", procedentes de Argentina, Chile y Bolivia, tuvieron un importante rol en el desarrollo del movimiento libertario del último país. Así, lo local se explica en relación con una dimensión regional. Se vuelve necesario, por lo tanto, ampliar la lente -como si estuviéramos observando a través de una cámara de fotos-, para poder advertir, no solo a Tupiza, Oruro o La Paz, sino a ese vasto espacio andino constituido por el Norte Grande. El mismo que, con sus características peculiares (la virtual ausencia del Estado, las fronteras porosas, la movilidad permanente), favoreció tal circulación. Mientras esos hombres se movían -desde, por ejemplo, Antofagasta a Iquique, en Chile o Tucumán a La Quiaca, en Argentina- creaban nuevas y utilizaban viejas redes de circulación e intercambio, que unieron en el tiempo, personal, material y simbólicamente, a los anarquismos del sur del continente.

El problema no fue atravesar la pampa salitrera o el norte argentino, ni siquiera llegar a Bolivia. Antes bien, una vez allí, la dificultad era enfrentar el castigo que pesaba sobre los "extranjeros apátridas": la expulsión. Se reactivaban así en muchos casos las redes, para volver al origen, para partir a otros lugares. Con esta práctica, de hecho, el Estado boliviano reconocía la impronta que los libertarios de los países vecinos podían llegar a tener en la formación de un movimiento local. $\mathrm{La}$ represión confirma ese "habitus internacionalista" y su efectividad, al intentar limitarlo.

La toma se convierte en una foto panorámica cuando continuamos uniendo puntos geográficos por medio de los vínculos que siguen generalmente las vías de los trenes. Las redes se enlazan, se entrecruzan, se hacen más complejas. Aparece la "red internacional de redes", en la que por ejemplo se integran Buenos Aires y Santiago, ciudades por fuera del Norte Grande pero de donde procedían -en primera instancia- muchos de los personajes protagonistas de nuestro relato. Incluso vimos que estos venían de más allá: España, Italia, Grecia. Así, el Atlántico y los Andes finalmente se conectan, cuando agrandamos el plano y logramos poner en diálogo el ámbito regional y transnacional.

Con esta captura podemos observar e incluir nuevos elementos en nuestro análisis. El sentido de las redes de circulación e intercambio no era, en modo alguno, unidireccional, desde un polo "de mayor desarrollo" al de "menor desarrollo" 
(por ejemplo, Argentina-Bolivia, Chile-Bolivia). Como vimos, las conexiones tenían direcciones múltiples. Del mismo modo, estas redes fueron igualmente prolíficas, en términos de su impacto, para todos los actores que se involucraron en ellas. Y así, el movimiento libertario de Buenos Aires o de Santiago en algún punto se nutrió y se vio potenciado con los hombres y las colaboraciones que llegaban desde La Paz, aumentando sus recursos materiales e ideológicos para sobrellevar el declive de comienzos de los 30 .
Pensar de acuerdo con el enfoque transnacional no es solo poner un signo de interrogación a la nación y al Estado. Se trata de concebir formas de espacialidad distintas y de utilizar nuevas categorías geográficas. También, de relativizar la idea de un desarrollo desigual, que conduce al establecimiento de relaciones de poder entre espacios. Después de todo, el anarquismo buscó -aunque no siempre lo logró- ser un movimiento internacionalista, antiestatista y horizontal. Disruptivo y radical en todas sus formas de pensamiento.

\section{Referencias Citadas}

Bantman, C. y B. Altena

2017 "Introduction: Problematizing Scales of Analysis in Network-Based Social Movements". En Reassessing the Transnational Turn. Scales of Analysis in Anarchist and Sindicalist Studies, editado por C. Bantman y B. Altena, pp. 3-22. PM Press, Oakland.

Barrio, Á.

2015 "La cultura política libertaria". En La Restauración y la República 1874-1936, coordinado por C. Forcadell y M. Suárez, pp. 255-284. Marcial Pons/Prensas Universitarias de Zaragoza, Madrid/Zaragoza).

Bovi, M. T.

2007 El Ferrocarril de La Quebrada. Estado, elites provinciales y los discursos sobre la modernidad en la construcción del Ferrocarril a Bolivia, 1880-1910. Actas de las Jornadas Interescuelas/Departamentos de Historia, Facultad de Filosofía y Letras, Universidad de Tucumán, San Miguel de Tucumán, Argentina.

Brangier, V.

2019 Editorial "Redes sociales en perspectiva histórica: casos de estudio en Suramérica, siglos XVII-XX”. Diálogo Andino 60, 2019: 3-7.

Cavieres, E. y F. Cajías (coords.)

2008 Chile-Bolivia, Bolivia-Chile: 1820-1930. Desarrollos políticos, económicos y culturales. Ediciones Universitarias de Valparaíso, Valparaíso.

Contreras, $\mathrm{M}$.

2003 "Bolivia, 1900-1939: Minería, ferrocarriles y educación”. En La era de las exportaciones latinoamericanas: de fines del siglo XXI a principios del XX, compilado por E. Cárdenas et. al., pp. 259-296. Fondo de Cultura Económica, México.

Ealham C.

2016 Vivir la anarquía, vivir la utopía. José Peirats y la historia del anarcosindicalismo español. Alianza Editorial, Madrid.

Fernández Cordero, L.

2017 "El periódico anarquista Nuestra Tribuna. Un diálogo transnacional en América Latina”, Anuario de Estudios Americanos 74:1: 267-293.

Ferrer, C.

2006 Cabezas de tormenta. Ensayos sobre lo ingobernable. Libros de Anarres, Buenos Aires.
Franco de Godoy, C. P.

2013 Ação direta: transnacionalismo, visibilidade e latência na formação do movimento anarquista em São Paulo (18921908). Tesis para aspirar al grado de Doctor en Sociología. Universidad de San Pablo, San Pablo, Brasil.

Galeano, D. y M. Albornoz

2017 "Anarquistas y policías en el atlántico sudamericano: una red transnacional, 1890-1910”. Boletín del Instituto de Historia Argentina y Americana "Dr. Emilio Ravignani" 47:101-134.

González Miranda, S.

2016 (Pay) Pampa. La presencia boliviana e indígena en la sociedad del salitre. RIL editores, Santiago.

González Miranda, S. y S. Leiva Gómez

2016 "El Norte Grande durante el Ciclo del Salitre: La política salitrera y la política exterior en la formación de un espacio transfronterizo (Bolivia y Chile, 1880-1929)", Estudios Atacameños 52: 11-29.

González, M. J.

2015 "Raymond Carr: La biografía de un historiador". En La historia biográfica en Europa. Nuevas perspectivas, editado por I. Burdiel y R. Foster, pp. 491-518. Institución Fernando el Católico, Zaragoza.

Grez, S.

2007 Los anarquistas y el movimiento obrero. La alborada de “la Idea” en Chile 1893-1915. LOM Ediciones, Santiago. Grez, S.

2018 "Los muertos de la Plaza Montt. Imaginarios a partir de la Masacre Obrera del 21 de diciembre de 1907 en el puerto de Iquique-Chile". Diálogo Andino 55, 2018: 29-41.

Groppo, B.

2012-2013 "Los diccionarios biográficos del movimiento obrero: análisis comparado de un género científico". Políticas de la Memoria 13:13-21.

Laforcade, G. y K. Shaffer (eds.)

2015 In Defiance of Boundaries. Anarchism in Latin American History. Gainesville, University Press of Florida.

Lora, G.

1969 Historia del Movimiento Obrero Boliviano, 1900-1923. Los Amigos del Libro, La Paz.

Lora, G.

1970 Historia del Movimiento Obrero Boliviano, 1923-1936. Los Amigos del Libro, La Paz. 
Luengo, J.

2015 "Las élites liberales en la España del siglo XIX: entre biografía, prosopografía y redes". En La historia biográfica en Europa. Nuevas perspectivas, editado por I. Burdiel y R. Foster, pp. 219-240. Institución Fernando el Católico, Zaragoza.

Margarucci, I.

2020 "Del Atlántico a los Andes. Notas sobre las relaciones del anarquismo argentino y boliviano, 1922-1927". Anuario IEHS, 34, 2 (en prensa).

Margarucci, I. y E. Godoy Sepúlveda

2017 "El Centro de Estudios Sociales La Brecha y el internacionalismo ácrata en el Norte Grande (Chile, 1922-1924)". Revista Historia en Movimiento 4:57-69.

Margarucci, I. y E. Godoy Sepúlveda 2018 Anarquismos en confluencia. Chile y Bolivia durante la primera mitad del siglo XX. Editorial Eleuterio, Santiago.

Migueláñez, M.

2018 Más allá de las fronteras: el anarquismo argentino en el periodo de entreguerras. Tesis para optar al grado de Doctora en Historia. Universidad Autónoma de Madrid, Madrid, España.

Muñoz, V.

2009 Armando Triviño: Wobblie. Hombres, problemas e ideas del anarquismo en los años veinte. Vida y escritos de un libertario criollo. Editorial Quimantú, Santiago.

Neto de Oliveira, V.

2009 Nas aguas do Prata. Os trabalhadores da rota fluvial entre Buenos Aires e Corumbá. Editora da Unicamp, Campinas.

Pinto Vallejos, J.

2007 Desgarros y utopías en la pampa salitrera. La consolidación de la identidad obrera en tiempos de la cuestión social (1890-1923). LOM Ediciones, Santiago.

Rodríguez García, H.

2010 La Choledad Antiestatal. El anarcosindicalismo en el movimiento obrero boliviano (1912 - 1965). Libros de Anarres, Buenos Aires.

Santibáñez, C.

2018 "La IWW y el Movimiento Obrero en Chile: el caso de los obreros portuarios nortinos (1919-1923)". Diálogo Andino 55, 2018: 19-28.

Souza Cunha, E.

2018 Editar a revolta: edição e circulação de impressos anarquistas em Buenos Aires (1890-1905). Tesis para optar al grado de Magíster en Historia. Universidad de San Pablo, San Pablo, Brasil.

Taibo, C.

2018 Anarquistas de ultramar. Anarquismo, indigenismo, descolonización. Eleuterio, Santiago.
Tarcus, $\mathrm{H}$.

2013 "La biografía colectiva. Por un Diccionario de las izquierdas y los movimientos sociales latinoamericanos". Iberoamericana 13, 52: 139-154.

Van Der Walt, L. y S. Hirsch (eds.)

2010 Anarchism and Syndicalism in the Colonial and Postcolonial World, 1870-1940: The Praxis of National Liberation, Internationalism, and Social Revolution. Brill, Leiden.

\section{Fuentes documentales y archivísticas}

\section{Periódicos}

Adelante! (Tucumán)

Arte y Trabajo (Cochabamba)

Aurora Social (Tupiza)

Caras y Caretas (Buenos Aires)

El Diario (La Paz)

El Heraldo (Cochabamba)

El Marítimo. Publicación semanal de la Combinación Mancomunal de Obreros (Antofagasta)

El Nacional (Iquique)

El Sembrador (Iquique)

El Socialista (Antofagasta)

El Mercurio (Antofagasta)

El Trabajo (Tucumán)

El Trabajo. Publicación subvencionada por la sociedad Combinación Mancomunal de Obreros de Coquimbo (Coquimbo)

Humanidad. Revista Libertaria (Buenos Aires)

La Antorcha (Buenos Aires)

La Batalla (Santiago)

La Obra (Tucumán)

La Patria (Iquique)

La Protesta (Buenos Aires)

Tierra Libre (Tucumán)

Tribuna Libertaria (Santiago)

\section{Archivos}

Archivo Luis Cusicanqui, Colectivo Ch'ixi, La Paz. Correspondencia de Luis Cusicanqui Durán.

\section{Otras fuentes}

Salas Lavaqui, M (ed.)

1908 Trabajos y antecedentes presentados al supremo gobierno de Chile por la Comisión Consultiva del Norte. Imprenta Cervantes, Santiago.

\section{Notas}

1 Para un abordaje teórico e historiográfico del concepto de red véase Brangier, 2019.

2 En la elaboración del presente artículo optamos por el género biográfico en complemento con la historia social (enfoque sociobiográfico), ya que su patrón metodológico, al igual que el de los diccionarios biográficos contemporáneos
(Tarcus, 2013), nos permite analizar y comparar trayectorias individuales a base de criterios generacionales, sociales, de instrucción y experiencias políticas previas, etc., para deducir reglas generales. No utilizamos así el enfoque prosopográfico (Groppo, 2012-2013), ya que no es nuestra intención establecer tipificaciones y periodizaciones de la 
acción militante colectiva en el Norte Grande, sino más bien nos interesa la "movimientalidad" de algunos anarquistas, la que nos permite recomponer las redes transfronterizas en dicho espacio geográfico a partir de esos sujetos "nodos". Para un ejemplo práctico de la utilización del enfoque biográfico en complemento con la prosopografía y el análisis de redes, véase Luengo (2015).

3 Estos lazos son tempranos. Se remontan a noviembre y diciembre de 1923, cuando Cusicanqui tras la fundación de La Antorcha, entabla relación epistolar con dos agrupaciones: Armonía y Brazo y Cerebro (Juan Coronel [ACA Armonía] y Victorio Vetulli [ACA Brazo y Cerebro]. "Cartas a Luis Cusicanqui", Tucumán, 2 de noviembre de 1923 y 25 de diciembre 1923). Probablemente los contactos con Tomás Soria daten de esta época, siendo que fue un activo miembro y secretario desde los inicios de Brazo y Cerebro ("Agrupación C. Anarquista Brazo y Cerebro", Tierra Libre, mayo de 1922; "Decíamos ayer...", Adelante!, febrero de 1923). 